\title{
Development and evaluation of the Interactive Network Language Teaching Platform Based on SNS and Web
}

\author{
Yujie Chang \\ Zhengzhou University of industrial technology, Henan, China
}

\begin{abstract}
This article in the context of the situation, the author proposes an open management model of teaching resources constructed under the Microsoft. NET platform based on SNS and Web services technology. Finally, a roadmap for the system and key implementation technologies are analyzed and the structural design of the system is established, presents the design idea of the interactive network teaching platform based on SNS, and then designs the interactive network teaching platform.
\end{abstract}

Keywords: SNS; Interactivity; Network teaching platform; System design.

\section{Introduction}

The design idea of the traditional network teaching platform with the resources as the center ignores the subjective initiative of the teaching subjects, lays too much emphasis on the basic teaching functions, and the interaction functions are insufficient, with no attention on the social philosophy, and the sense of belongings and cohesion of the learning community is not enough [1-3]. Aiming at the shortages of the traditional network teaching platform, based on the related network teaching theories, combined with the advantage of the interactivity of the SNS, The network teaching platform is not only a developing and changing concept, but also a concept of a broad connotation. At present, the network teaching platform theory is not mature, and there is no unified concept. So it is necessary to define the definition of the network teaching platform. The network teaching platform in this paper refers to the software environment of the network teaching. The following are some common definitions [4-7].

\section{The connotation and characteristics of SNS}

Social networking (SN) refers to the network of relationships between people. The web site based on the ideas of the network relationship system is the social networking site (SNS). Web 1.0 networks are used just as the information dissemination tool, and the majority of the network users are the recipients of the information. Compared with the traditional web 1.0 era, SNS as the representative of the Web 2.0 has the following characteristics:

\subsection{The establishment of the virtual communities on the basis of the personal preferences}

In the environment of SNS, the teaching subjects with the same interests can establish the learning interest groups in the form of learning communities. The interpersonal circle is established not only on the basis of the relationship of your relatives, friends, and classmates, but also on the basis of common interests, topics, and the common experiences. Based on the support of such databases, by mining the user information, it is possible to get the users' preferences, and to track the behaviors of the users.

The related researches of SNS in the aspect of the application of pedagogy are: (1) studies of the advantages of the network teaching application of SNS. The articles on behalf are "Analysis of the potential applications of SNS in the teaching", which analyzes systematically the advantages of SNS in teaching from the propagation properties and characteristics of SNS, and forecasts the application prospects of SNS in teaching. "Preliminary exploration on the construction of the web-based learning environment with the application of the website functions of SNS" researches on the advantages of the SNS sites of the formation of the network learning environment from the aspect of the construction of the network environment, and obtains the application values of SNS in the construction of the learning environment. (2) Discussion on the theory of the construction of the 
network learning community using SNS. The representative articles are "Preliminary exploration on the construction of the inter-school network learning communities based on SNS", which puts forward the community structures on the basis of the analysis of the characteristics, and "Study of the construction of the network learning community based on the SNS", which constructs an SNS-based network learning community based on the analysis of the existing network learning community and the advantages of the SNS. (3) Inspiration of SNS for the teaching reform. "Discussion of teaching reform of the microcomputer principles and the interface technologies based on SNS" proposes the reform of the teaching methods using SNS according to the specific curriculum teaching, in order to improve the teaching efficiency. (4) Study on the application of SNS in teaching. "Research on the thematic collaborative learning platform based on the SNS" combines SNS with the thematic collaborative learning. "Study and application of the Web 2.0 techniques in the network teaching platform" applies each specific technology of Web 2.0 to different aspects of the network teaching, and conducts the functional application from the local areas. "Construction of the social interactive environment in the network teaching platform based on the Blog" applies the Blog to the network teaching, to realize the function of the interactivity of the network teaching.

\subsection{Technical feasibility}

Four methods can be used to achieve the construction of the network learning platform with the aid of the SNS: transplant the SNS concepts into the existing network teaching platform, build the platform with the aid of the SNS, conduct the secondary development using the open-source codes, and carry out the development using the technical structures of the SNS network.

\subsection{The SNS concepts into the existing network teaching platform}

The network teaching platform is the infrastructure in the network teaching system, with mature and complex technologies. We are unable to achieve the seamless combination if we rigidly embed the SNS system in the original teaching platform, and we can transplant the partially improved functions into the SNS platform. SNS as a social network service also can be said to be a kind of philosophy. The concept of the combination of the individual with the community, the characteristics of the interpersonal support, and the idea of SNS is used in the existing platform, as an extension of the supportive services of the existing platform, to meet the needs of the social support of the learners. At the same time, the idea of SNS is used in the mature platform, and the changes to the original platform is relatively small, which will save the costs, and the difficulty will be relatively low.

\subsection{Build the platform using the mature SNS website}

Since 1997, SNS has developed so far, and has mature technology and a wide range of audience. There are various types of SNS because of the diversity of the audience, and the objects using a SNS focus on the adolescents, and the majority of the existing SNS site can be free to use through the registration, and can be used to as the auxiliary communication platform of the network teaching, which is available to use and can save the resources. But because there are many interfering advertising information, on the webpage of a lot of the open SNS websites because of the profit demand, the rich game functions on the part of the SNS site have also become a factor to consider. In the selection of the SNS platforms for the teaching, we should exclude the interference information as far as possible.

In the exploration of the main contents of the platform of SNS application, we should fade the entertainment coat, and provide free plug-in, and by encouraging the use of the educational researchers, entrepreneurs and others, we should develop the new scope of application of SNS. The current representative academic SNS is the Ning site, and there is the feasibility analysis of integrating cooperative learning website SNS and the thematic collaborative learning in the application of the education.

Track and record the learning behaviors of the learners, reduce the loneliness of the learners, and arouse the participation and enthusiasm of the learners.

In the traditional learning environment, the learning atmosphere is very important factor to influence the learning effect, and the good and positive learning environment can stimulate the learning desire of the learners to have the autonomous learning. In the traditional classroom learning environment, the learning atmosphere refers to the surrounding atmosphere that can be felt, and the 
actions, or dialogues, or learning, or readings, or the actions of doing exercises of the other learners that can be perceived. And in the network learning platform, in our own learning space, we do not know whether the other learners are involved in the subjects, view the dialogues, or vote. In the traditional network teaching environment, teachers through the heterogeneous grouping, select the learning team leaders, and make clear the division of the labor. In the model of the theme grouping based on the SNS, teachers create large theme modules, which can be divided into small modules. The learners according to their own interests are free to participate in the SNS social space themes, and can join in multiple large theme modules that the teachers create. The learners have their own personal space, and the learners can create a different theme module according to their own hobbies, and can join in a module of other students that they are interested in, and each student can find the learning partners most suitable for their personality to improve the learning interests.

\section{Design of function}

\subsection{Integration and Convergence of Teaching Resources}

Information integration is the merging of information from heterogeneous sources with differing conceptual, contextual and typographical representations. Open management platforms for teaching resources are designed to integrate and collect digital learning resources originating from university units at present or in the future, on the condition that digital resources' rights protection are respected and applied to all kinds of often valuable educational resources that need to be reorganised and filed in the university central database for optimal usage.

With technical assistance to process and integrate the resources, as well as strategy to ensure quality in selection and evaluation, the central resource database will grow quickly and sustainably. Also, a resource data centre of teaching programmes needs to be formed at universities to allow data integration and sharing between educational administrative units or a commercial teaching resource library.

\subsection{Data Service of Teaching Resources}

The value of teaching resources is reflected in their use. The resource platform provides access to services within the platform to authorised users or other learning management systems, such as Blackboard, in the form of Web services [3].

Due to differences in format and size, various qualities, diverse ownership and other issues, it is unrealistic to expect that all teaching resources in a given university will be integrated and stored in the teaching resources data centre at that university.

This article focuses on platforms operating on open service principles for managing resources, whose provider has the right to determine authorisation and access to the data resources centre and decides on the scope, objectives and the way to use the resources. Deciding on the appropriate resource assessment policy is crucial to ensure the quality of resources, their proper integration and promotion for teaching and learning.

\subsection{Resource Assessment}

In resource evaluation, based on a particular strategy, several quality measures need to be considered, including metadata standardisation, resources (software) quality, resource applicability, usage statistics (i.e. number of visits or access to resources).

\section{The technical route and key technologies}

The Microsoft Windows platform provides a powerful graphical interface and numerous multimedia functions, like free integrated bundled Windows media technology (WMT) and others, which form the current mainstream of the operating system platforms used in Chinese universities. .NET, as the third-generation network platform developed by Microsoft, introduced the new .NET framework on the platform and executes the application through a consistent common language runtime (CLR). The .NET platform stimulates the development mode, reducing a lot of work for programmers, including repeat code, systems maintenance and other aspects [4]. 
For example, data exchange and message transfer mechanisms based on SNS and SOAP and combined with Web services technology, can provide information services across platforms; another example, with the help of access interface of SQL server available internally and the optimised SQL server database: system.data.sqlclient being provided via ADO.NET, programmers can easily carry out operations in the SQL operation server database. Therefore, considering the practices and ease of development, the author of this articles has chosen Microsoft Windows and .NET as the technical line for the resource management platform (Figure 1).

\begin{tabular}{|c|c|c|}
\hline $\begin{array}{l}\text { Application for using Web } \\
\text { Teaching resource }\end{array}$ & Binding & $\begin{array}{l}\text { Providing services of Web } \\
\text { teaching resource }\end{array}$ \\
\hline
\end{tabular}

Figure 1: Resource service model based on Web services.

\section{Conclusion}

In this paper, the author researches on the interactive network teaching platform based on the SNS environment, with the following main contributions: It mainly includes the design of the teaching interactive features, the evaluation and feedback functions and the social sustaining functions, and gives the design processes of each module. By analyzing the design ideas and the functional framework of the traditional network teaching platform, we can obtain the shortages of the traditional network teaching platform. The traditional network teaching platform pays too much attention to the basic functions of the teaching, and the interactive function is weak, which pays the inadequate attention to the subjective initiative of the teaching subjects, and ignores the construction of teaching situations. Based on this, this paper presents the design ideas and methods of the interactive network teaching platform based on SNS. The design ideas of the interactive network teaching platform are based on the interactive thought and humanistic thought. The design idea based on SNS in this paper pays more attention to the status of the masters of the teaching subjects, and pays more attention to the interaction between the teaching subjects.

\section{References}

[1] Mu Rongjun. Design and development of the remote collaborative learning platform based on the Web (Web CL) [J], Modern Distance Education, 2002, 3, (2): 44-46

[2] Yu Shengquan, He Kekang. The structures and functions of the network teaching platform [J], Chinese audio-visual education, 2001, 3, (8): 60-63

[3] Xie Xiaolin, Yu Shengquan, Cheng Gang, Huang Yemin. Research on the new development of the open education of the network teaching platform [J], 2007, 13, (5): 12-25

[4] SNS. Wikipedia, 4 February 2016, https://en.wikipedia.org/wiki/SNS

[5] Qi, B., Research and application of role based privilege management model in the innovation project management system of college students. Software Guide, 3, 110-112 (2011).

[6] Zhao, H. and Chen, X., The Design and realization of an open style instruction resource management model which based on SNS \& Web services. Modern Educational Technol., 6, 77-80 (2006).

[7] Bose, R. and Sugumaran, V., Challenges for deploying Web services-based e-business systems in SMEs. Inter. J. of E-business Research, 2, 1-18 (2008). 